\title{
Analysis of Contributing Factors to Desertification and Mitigation Measures in Basilicata Region
}

\author{
Bruno Basso ${ }^{* 1}$, Lorenzo De Simone ${ }^{1}$, Agostino Ferrara ${ }^{1}$, Davide Cammarano $^{2}$, \\ Giovanni Cafiero ${ }^{1}$, Mei-Ling $\mathrm{Yeh}^{3}$, Tien-Yin $\mathrm{Chou}^{3}$ \\ ${ }^{1}$ Department Crop Systems, Forestry and Environmental Sciences, University of Basilicata \\ Via dell'Ateneo Lucano 10, 85100 Potenza, Italy \\ ${ }^{2}$ Institute for Sustainable Resources, Queensland University of Technology \\ GPO Box 2434 Brisbane, Australia \\ ${ }^{3}$ GIS centre, Feng Chia University, Department of Land Management, FCU campus, \\ 100, Wenhwa Rd., Taichung, Taiwan 40724, Republic of China
}

Received: 29 December 2009. Accepted: 12 April 2010.

\begin{abstract}
Soil, vegetation, climate and management are the main factors affecting environmental sensitivity to degradation, through their intrinsic characteristics or by their interaction with the landscape. Different levels of degradation risks may be observed in response to particular combinations of the aforementioned factors. For instance, the combination of inappropriate management practices and intrinsically weak soil conditions will result in a degradation of the environment of a severe level, while the combination of the same type of management with better soil conditions may lead to negligible degradation.

The objective of this study was to identify the factors responsible for land degradation processes in Basilicata and to simulate through the adoption of the SALUS soil-plant-atmosphere system model potential measures to mitigate the processes. Environmental sensitive areas to desertification were first identified using the Environmental Sensitive Areas (ESAs) procedure. An analysis for identifying the weight that each contributing factor (climate, soil, vegetation, socio-economic management) had on the ESA was carried out and successively the SALUS model was executed to identify the best agronomic practices. The best agronomic management practice was found to be the one that minimized soil disturbance and increased soil organic carbon. Two alternative scenarios with improved soil quality and subsequently improving soil water holding capacity were used as mitigation measures. The new ESA were recalculated and the effects of the mitigation suggested by the model were assessed.
\end{abstract}

Key-words: salus model, ESAs, Mediterranean desertification, mitigation measures, GIS.

\section{Introduction}

Mediterranean region have been experiencing severe ecosystem degradation for centuries due to inappropriate land management on steep slopes and more frequent periods of droughts. Marginal areas with poor soil not suitable for agriculture have been put to cultivation, thus increasing soil erosion and soil organic matter levels decline which has lead to progressive land degradation processes with reduction in the vegetation cover with respect both to biodiversity and productivity. The development of high input agriculture in the plains provided much higher net financial outputs than those obtained from hilly areas agriculture causing a migration of people to this areas and consequently a land abandonment of the hilly areas. In the flat areas, though, overexploitation of the groundwater is resulting in soil salinization, deterioration of soil physical properties with adverse effects on plant growth.

In a global contest, Desertification is defined by the UNCCD as "Land degradation in arid, semi-arid and dry subhumid areas resulting from various factors, including climatic variations and human activities". This degradation is caused by uncontrolled forest destruction, wa-

\footnotetext{
* Corresponding Author: Tel.: +39 3204371042; Fax: +39 0971205378. E-mail address: bruno.basso@unibas.it.
} 
ter pollution, wind and water erosion, salinisation, and inadequate soil management under both cultivated and uncultivated regimes. One of the major problems affecting the soil is the severity with which the degradation processes reduce soil biological potential. An unsustainable, rapid reduction, which cannot be mitigated using appropriate mechanisms, leads, consequently, to desertification (Thornes, 1995).

Environmental Sensitivity to desertification can be defined, in this context, as the response of the environment, or part of it, to a change in one or more external factors (Basso et al., 2000).

Detailed analysis of the causes and manifestation of degradation require plot scale data, whereas identification, management, and monitoring require continuous data over large areas. The use of a GIS also facilitates the establishment of standardised procedures to integrate alphanumeric and cartographic data with remotely sensed information (Corona et al., 1991; De Jong, 1994; Ferrara et al., 1995; Yassoglu et al., 1995; Basso et al., 2000a, 2000b) and other kinds of data.

The objective of this study was to identify the factors responsible for land degradation processes in Basilicata and to simulate through the adoption of a soil-plant-atmosphere system potential measures to mitigate the processes. Environmental sensitive areas (ESAs) to desertification were first identified using the Environmental Sensitive Index procedure (ESI; Basso et al., 2000b). An analysis for identifying the weight that each contributing factor (climate, soil, vegetation, management) had on the ESA was carried out and successively the SALUS model was executed to identify the practices and the areas where the soil could have been improved. The new ESA were recalculated and the effects of the mitigation suggested by the model were assessed.

\section{Environmental Sensitive Area Methodology}

The methodology of the calculation of environmental sensitive area has been developed as results of the Medalus Projects (I, II, III, IV) and is describe in Basso et al., 2000a. The Environmental Degradation or Sensitivity of an area is a broad concept, since, depending on context, it can be defined by many different factors, often operating in association. An Environmental Sensitive Area (ESA) can be considered, in general, as a specific and delimited entity in which environmental and socio-economical factors are not balanced or are not sustainable for that particular environment. The ES to degradation or desertification of an area can also be seen as "the result of the interactions among elementary factors(information layers)that are differently linked to direct and indirect degradation or desertification phenomena" (adopted by Basso et al., 2000). Severe, irreversible environmental degradation phenomena, for example, could result from a combination of inadequate land management together with a particular set of critical environmental factors: soil, climate and vegetation. The particular set depends on the particular management and environment. From this perspective, a system which summarizes and characterizes the main elements, and their interrelationships, which combine to create particular critical situations, of varying severity, would be a very useful tool for decision-makers.

Two of the most important sets of parameters which affect an environment's sensitivity to degradation are the ecological and socio-economical ones. ES is closely related to many environmental factors such as climate, soil, vegetation cover, and morphology where their characteristics, and their intensity, contribute to the evolution and characterization of different degradation levels or stages. Sensitivity is also strongly linked to socio-economic factors since man's behaviour and his social and economic actions can greatly influence the evolution of numerous environmental characteristics.

The current working set of thematic layers, used in the GIS to assess ES to desertification in the Basilicata Region is given in Tables 1-3. In this scheme, scores were assigned to the elements of a particular parameter with valid scores ranging from 1 , the best conditions, to 2 , the worst conditions. A value of 0 was assigned to areas where a measure was not a ppropriate and thus unclassified. This scheme means that the layer results are independent of the structure, number of classes, etc. This, in turn, means that the layers can be compared on an equal basis, irrespective of the original data format, and higher level processing is decoupled from the details of the data, and layers can be revised or 
developed without affecting the remaining structures. The classes and scores assigned were based on the influence and strength of the association that the different layers have with the soil degradation processes and their relationships to the onset of irreversible degradation or desertification phenomena (FAO, 1976; Briggs et al., 1992; Kosmas et al., 1994, 1997; Poesen and Bunte, 1996; Basso et al., 1997.). In this paper, the scale is linear between the extremes, other, non-linear, scales are obviously possible and might even be desirable under certain circumstances but this is an area which needs further research. A more comprehensive description on how the environmental layers are linked to the degradation or desertification phenomena is given in the works of Basso et al., 1998, 2000; Kosmas et al., 1994, 1998). Incorporation of socio-economic data is more problematic. These data are important in order to evaluate the interactions of mankind with the environment, but their intangibility make them difficult to define. Many indicators have been evaluated to find out their link, through their spatial distribution, to landscape degradation (Marotta and Quaranta, 1996). Each elementary unit in each Quality Layer is estimated as the geometric mean of its own sub-layers:

$\begin{aligned} & \text { Quality_x } \text { ij }= \\ &\left(\text { layer_1 } 1_{\mathrm{ij}} * \text { layer_2 } 2_{\mathrm{ij}} * \text { layer_n } \mathrm{n}_{\mathrm{ij}}\right)(1 / \mathrm{n}) \mathrm{lay} \_3_{\mathrm{ij}} * \\ & {[1] }\end{aligned}$ where: $\mathrm{i}, \mathrm{j}=$ rows and columns of a single elementary pixel $(30 \times 30 \mathrm{~m})$ of each layer;

$\mathrm{n}=$ number of layers used

The first level, that of the basic data layers, isolates the rest of the system from the details of the data. The quality layer, level 2 , acts as a buffer between the level 1 data layers and the derived ESA layer, level 3. The weight of each quality layer is equivalent so, as with the level 1 components, the results are comparable amongst the layers and the constituents of a particular layer are hidden from the rest of the system. This approach allows the overall abstract "quality" themes (or contexts: soil, climate, vegetation and management), which make up each quality layer, to be developed independently and without changing the structure of the overall methodology. With the four qualities obtained from the above, the ES is estimated by:
$\mathrm{ES}_{\mathrm{ij}} \quad=\left(\right.$ Quality_1 $_{\mathrm{ij}} *$ Quality_2 ij $_{\mathrm{ij}} *$ Quality _3 $3_{\mathrm{ij}} *$ Quality _4 $\left.4_{\mathrm{ij}}\right)^{(1 / 4)}$
where: $\mathrm{i}, \mathrm{j} \quad$ = rows and columns of a single [2] elementary pixel $(30 \times 30 \mathrm{~m})$ of each quality;
Quality_ $\mathrm{n}_{\mathrm{ij}}=$ computed values

The structure gives equal weights to each level_1 layer when computing each quality (e.g. soil texture has the same weight as other soil layers) and equal weights to each quality in level_2 when computing the final ES irrespective of the number of contributing level 1 layers; i.e. a single climate parameter has, in this case, a higher influence than a single soil parameter. By doing this, the higher level computations in the model are unaffected by the number of level 1 layers; this means that a component of the quality layer is not penalised because it does not have many information layers, nor is it exaggerated if it is well specified with many layers.

\section{Construction of the Geo-Database}

All input data was structured in a Geo-Database using Esri Arc GIS: shapefiles were harmonized in a feature dataset using UTM 33N coordinate system and implementing basic topology rules to filter out any eventual geometric error. Input data retrieved in tabular format form the original sources, was converted in .dbf format and uploaded in the Geo-Database as well.

\subsection{Data collection}

A semi-detailed survey of the above land parameters have been conducted during the execution of the European Commission funded research project of MEDALUS (Mediterranean Desertification and Land Use). Part of the data related mainly to rainfall, air temperature, geology and topography have been collected from already existing data bases. Soil data such as soil texture, depth to bedrock, stoniness, and drainage have been measured in a dense network of field observations. The boundaries of the mapping units were drawn on topographic maps of scale 1:50.000. Vegetation was defined on the basis of the dominant species such as macchia, shrubs, olives, pines, evergreen or deciduous oaks, cereals, etc. Plant cover was determined from aerial photo-interpretation and 
ground data at a scale 1:30.000. All these data have been introduced to Geographical Information Systems (GIS) and the corresponding maps of the land parameters used for the comparison of the target areas have been derived, and the area corresponding to the various classes of each parameter was determined (Ferrara et al., 2005).

\subsection{Description of the biophysical quality layers}

\section{Soil quality}

Soil is one of the most important factor of the terrestrial ecosystem due to its crucial role in providing physical support and supply of nutrients to the plants. Soil quality varies with respect to its organic matter content and water availability. These qualities can be evaluated using simple soil properties or characteristics given in regular soil survey such as texture, parent material, soil depth, slope gradient. In this study soil data were retrieved from the soil map of Basilicata released by Regione Basilicata in 2005. The nominal scale of the map is 1:250.000, and constitutes a compromise between data generalization, intensity of soils surveys (1300 soil profiles from March 2002 through April 2004). Overall, a total of 154 soil types have been classified in the map, and labelled according the STU (Soil Typological Unit). USDA's Soil Taxonomy was as well used as a reference for the definition of taxonomic aspects. Furthermore, to facilitate the integration of such a regional database into the more general national one, the silt types were also classified according to the World Reference Base (WRB) which has been developed by FAO and ISRIC in 1998. The resulting soil map was converted in ARCGIS shapefile format and implemented in this study. The shapefile featured 485 records each representing a single spatial entity linked to the geo-litho-pedologic characterization contained in the soil atlas.

\section{Soil texture}

Soil texture is related to erodibility, water retention capacity, crusting and aggregate stability. The amount of available water is related to both texture and structure. Soils with high amount of silt tend to have high water holding capacity. Sandy soils tend to be more droughty than clayey soils because the former retain less water at field capacity. The soil textural classes are grouped according to their water-holding capacity in four classes (Tab. 1).

\section{Parent material}

Soils derived from different parent materials react differently to soil erosion, vegetation and desertification. For example, limestone produces shallow soils with a relatively dry moisture regime. In the opposite soils formed in plysh are deep, well vegetated and protected from erosion. Several areas on limestone formations in the Mediterranean region are already desertified with the soil mantle eroded, and the vegetation cover completely removed. Similarly, acid igneous parent materials such as pyroclastics produce shallow soils, with high erodibility and high desertification risk. As Table 1 shows, the various parent materials can be classified for their sensitivity to desertification into three classes.

\section{Rock fragments}

Rock fragments present in the soil surface have a great but variable effect on runoff and soil erosion (Danalatos et al., 1995), soil moisture conservation (Wesemael et al., 1995; Moustakas et al., 1995) and biomass production, so playing an important role on land protection in the Mediterranean region. Rock fragments present in the soil surface are classified in three classes according to their capacity to conserve soil water and protect the soils from erosion (Tab. 1).

\section{Soil depth}

Soils in hilly areas formed on consolidated parent materials usually have a shallow limiting layer due to the presence of bedrock at certain depth restricting the ability to support a considerable vegetation cover under Mediterranean climatic conditions. Below a critical depth depending on the parent material, the woody plant species disappear (Kosmas et al., 1998) and only some annual plants can survive. The erosion rate below the critical depth is very high, favouring the appearance of the underlying bedrock on the surface. Soil depth is defined as the depth of the soil profile from the soil surface to the top of the regolith or unweathered parent material and it is classified into four classes (Tab. 1). Soil depth is considered as one of the most important soil parameters greatly affecting desertification and therefore a higher weighing factor is assigned to this parameter. 
Table 1. Classes, description and assigned weighing indices used for soil quality index assessment.

\begin{tabular}{lllc}
\hline \multicolumn{2}{l}{ Texture } \\
\hline Class & Description & Texture & Index \\
\hline 1 & Good & L, SCL, SL, LS, CL & 1 \\
2 & Moderate & SC, SiL SiCL & 1.2 \\
3 & Poor & Si, C, SiC & 1.6 \\
4 & Very poor & S & 2 \\
\hline
\end{tabular}

\section{Parent material}

\begin{tabular}{|c|c|c|c|}
\hline Class & Description & Parent material & index \\
\hline 1 & Good & $\begin{array}{l}\text { Shale, schist, basic, } \\
\text { ultra basic, conglomerates, } \\
\text { unconsolidated }\end{array}$ & 1.0 \\
\hline 2 & Moderate & $\begin{array}{l}\text { Limestone, marble, granite, } \\
\text { Rhyolite, gneiss, sandstone }\end{array}$ & 1.7 \\
\hline 3 & Poor & Marl, Pyroclastics & 2.0 \\
\hline
\end{tabular}

\section{Rock fragment}

\begin{tabular}{lllc}
\hline Class & Description & RF cover $(\%)$ & Index \\
\hline 1 & Very stony & $>60$ & 2 \\
2 & Stony & $20-60$ & 1.3 \\
3 & $\begin{array}{l}\text { Free to } \\
\text { slightly stony }\end{array}$ & $<20$ & 1 \\
\hline
\end{tabular}

\section{SLOPE}

\begin{tabular}{lllc}
\hline Class & Description & slope $(\%)$ & Index \\
\hline 1 & Very gentle & & \\
& to flat & $<6$ & 1 \\
2 & Gentle & $6-18$ & 1.2 \\
3 & Steep & $18-35$ & 1.5 \\
4 & Very steep & $>35$ & 2 \\
\hline
\end{tabular}

\section{SOIL DEPTH}

\begin{tabular}{lllc}
\hline Class & Description & depth $(\mathrm{cm})$ & index \\
\hline 1 & Deep & $>75$ & 1 \\
2 & Moderate & $75-30$ & 2 \\
3 & Shallow & $15-30$ & 3 \\
4 & Very shallow & $<15$ & 4 \\
\hline
\end{tabular}

\section{DRAINAGE}

\begin{tabular}{llc}
\hline Class & Description & index \\
\hline 1 & well drained 1 & \\
2 & Imperfectly drained & 1.2 \\
3 & Poorly drained 2 & \\
\hline
\end{tabular}

\section{SOIL QUALITY}

\begin{tabular}{llc}
\hline Class & Description & range \\
\hline 1 & high quality & $<1.13$ \\
2 & moderate quality & 1.13 to 1.45 \\
3 & low quality & $>1.46$ \\
\hline
\end{tabular}

\section{Slope gradient}

Slope angle and generally topography is undoubtedly considered as one of the most important determinants of soil erosion. Erosion becomes acute when slope angle exceeds a critical value and then increases logarithmically. Slope grade is classified in four classes according to the effect on soil erosion (Tab. 1).

\section{Drainage}

Soil drainage condition is mainly used for assessing desertification risk due to salinization of flat areas located mainly in alluvial plains along the coastal line or in depressions inside valleys. Three drainage classes are classified with respect to their effect on salinization (Tab. 1) taking into consideration the depth of ground water table and the presence of hydromorphic characteristics such as iron and maganese mottles or concretions.

Soil quality index (SQI) is then calculated as the product of the above parameters, namely soil texture, parent material, rock fragment content, soil depth, slope grade, and drainage conditions using the following equation:

$$
\begin{aligned}
\mathrm{SQI}= & (\text { texture } * \text { parent material } * \mathrm{RF} * \\
& \text { depth } * \text { slope } * \text { drainage })^{1 / 6}
\end{aligned}
$$

The soil quality index is then scaled into three categories with respect to water availability and erosion resistance (Tab. 1).

\section{Climate quality}

Climate quality is assessed using parameters that influence water availability to the plants such as amount of rainfall, air temperature and aridity. Annual precipitation is classified in three classes considering the annual precipitation of $280 \mathrm{~mm}$ as a crucial value for soil erosion (Kosmas et al., 1997) and plant growth (Tab. 2).

The most effective measure of soil water availability is the assessment of precipitation minus evapotranspiration and run-off. However, this calculation requires relatively many data such as soil moisture retention characteristics, vegetation growth characteristics etc., therefore, the simple Bagnouls-Gaussen aridity index is used here. The Bagnouls-Gaussen aridity index (BGI) is defined as following:

$$
\mathrm{BGI}=\sum_{\mathrm{i}=1}^{\substack{\left(2 \mathrm{t}_{\mathrm{i}}-\mathrm{Pi}\right) \cdot \mathrm{k}\\}}
$$


Table 2. Classes, description and assigned weighing indices used for climate quality index assessment.

\begin{tabular}{llc}
\hline Rainfall & & \\
\hline Class & Rainfall $(\mathrm{mm})$ & Index \\
\hline 1 & $>650$ & 1 \\
2 & $280-650$ & 2 \\
3 & $<280$ & 4 \\
\hline
\end{tabular}

\section{CLIMATE QUALITY}

\begin{tabular}{llc}
\hline $\begin{array}{l}\text { Climate } \\
\text { quality index }\end{array}$ & Description & Range \\
\hline 1 & High quality & $<1.15$ \\
2 & Moderate quality & 1.15 to 1.81 \\
3 & Low quality & $>1.81$ \\
\hline
\end{tabular}

\section{ARIDITY}

\begin{tabular}{llc}
\hline Class & BGI range & Index \\
\hline 1 & $<50$ & 1 \\
2 & $50-75$ & 1.1 \\
3 & $75-100$ & 1.2 \\
4 & $100-125$ & 1.4 \\
5 & $125-150$ & 1.8 \\
6 & $>150$ & 2 \\
\hline
\end{tabular}

where: $t_{i}$ is the mean temperature for month $i$, $P_{i}$ is the total precipitation for month $\mathrm{i}$; and $\mathrm{k}_{\mathrm{i}}$ represents the proportion of the month during which $2 \mathrm{t}_{\mathrm{i}}-\mathrm{P}_{\mathrm{i}}>0$. The Bagnouls-Gaussen bioclimatic index is classified into six classes as in Table 2.

Slope aspect is considered also as affecting microclimatic conditions. Slope aspect is divided into two classes (a) NW and NE and (b) SW and SE assigning the indices 1 and 2, respectively. Finally the climate quality index (CQI) assessed by the equation and Table 2 :

$$
\mathrm{CQI}=(\text { rainfall } * \text { aridity } * \text { aspect })^{1 / 3}
$$

\section{Vegetation quality}

Vegetation quality is assessed in terms of (a) fire risk and ability to recover, (b) erosion protection to the soils, (c) drought resistance, and (d) plant cover.

\section{Fire risk and ability to recover}

Forest fires are the most important causes of land degradation in the Mediterranean region. Fires have become very frequent especially in the pine dominated forests with dramatic consequences in soil erosion rates and biodiversity losses. The frequency of fire occurrence is lower in grasslands, and mixed Mediterranean macchia with evergreen forests. Also, Mediterranean pastures are frequently subjected to man-induced fires for regenerating higher annual grass production. The Mediterranean vegetation type is highly flammable and combustible due to the existing of species with high content of resins or essential oils. The dominant types of vegetation prevailing in the Mediterranean are grouped in four classes (Tab. 3).

\section{Soil erosion protection}

Vegetation and land use are clearly important factors, controlling the intensity and the frequency of overland flow and erosion (Bryan and Campbell, 1986; Mitchell, 1990). Extensive areas cultivated with rainfed crops such as cereals, vines, almonds and olives are mainly confided to hilly lands with shallow soils very sensitive to erosion. These areas become vulnerable to erosion and desertification because of the decreased protection by vegetation cover in reducing effective rainfall intensity at the ground surface (Faulkner, 1990). Perennial crops such as almonds, and olives have largely expanded in Mediterranean hilly areas, while vines have declined during the last decades (Grove, 1996). These crops require frequent removal of annual vegetation using pesticides. Actually, such soils remain almost bare during the whole year, creating favourable conditions for overland flow and soil erosion. The various types of vegetation are classified in five classes (Tab. 3) with respect to erosion protection to the soils.

\section{Drought resistance}

The various ecosystems found in the Mediterranean region present a great capacity of adaptation and resistance to aridity because most of the species existing under Mediterranean climatic conditions have to survive under long droughts and soil moisture contents below the theoretical wilting point for many months. The various types of vegetation prevailing in the Mediterranean are classified in four classes according to the drought resistance (Tab. 3).

\section{Plant cover}

Many authors have demonstrated that in a wide range of environments both runoff and sedi- 
Table 3. Classes, description and assigned weighing indices used for vegetation quality index assessment.

\begin{tabular}{lllc}
\hline Fire risk & & & \\
\hline Class & Description & Type of vegetation & index \\
\hline 1 & Low & $\begin{array}{l}\text { Bare land, perennial agricultural crops, annual agricultural } \\
\text { crops (maize, tobacco, sunflower) }\end{array}$ & 1 \\
2 & Moderate & $\begin{array}{l}\text { Annual agricultural crops (cereals, grasslands), deciduous oak, (mixed), } \\
\text { mixed Mediterranean, macchia/evergreen forests }\end{array}$ & 1.3 \\
3 & High & Mediterranean macchia & 1.6 \\
4 & Very high & Pine forests & 2 \\
\hline
\end{tabular}

\section{Erosion protection}

\begin{tabular}{lllc}
\hline Class & Description & Vegetation types & Index \\
\hline 1 & Very high & Mixed Mediterranean macchia-evergreen forests (with $Q$. ilex) & 1 \\
2 & High & Mediterranean macchia, pine forests & 1.2 \\
3 & Moderate high & Deciduous forests (oak mixed), permanent grassland & 1.4 \\
4 & Moderate & Evergreen perennial agricultural crops (olives) & 1.6 \\
5 & Low & Deciduous perennial agricultural crops (almonds, orchards) & 1.8 \\
6 & Very low & Annual agricultural crops (cereals), annual grasslands & 2 \\
\hline
\end{tabular}

\section{Drought resistance}

\begin{tabular}{lllc}
\hline Class & Description & Types of vegetation & Index \\
\hline 1 & Very high & Mixed Mediterranean macchia/evergreen forests, Mediterranean macchia & 1 \\
2 & High & Conifers, deciduous, olives & 1.2 \\
3 & Moderate & Perennial agricultural trees (vines, almonds, ochrand) & 1.4 \\
4 & Low & Perennial grasslands & 1.7 \\
5 & Very low & Annual agricultural crops, annual grasslands & 2 \\
\hline
\end{tabular}

\section{Plant cover}

\begin{tabular}{lllc}
\hline Class & Description & Plant cover $(\%)$ & Index \\
\hline 1 & High & $>40$ & 1 \\
2 & Low & $10-40$ & 1.8 \\
3 & Very low & $<10$ & 2 \\
\hline
\end{tabular}

\section{VEGETATION QUALITY}

\begin{tabular}{llc}
\hline Vegetation quality index & Description & Range \\
\hline 1 & high quality & $<1.13$ \\
2 & Moderate quality & 1.13 to 1.38 \\
3 & low quality & $>1.38$ \\
\hline
\end{tabular}

ment loss decrease exponentially as the percentage of vegetation cover increases (Elwell and Stocking, 1976; Lee and Skogerboe, 1985; Francis and Thornes, 1990). A value of $40 \%$ vegetative cover is considered critical below which accelerated erosion dominates in a sloping land (Thornes, 1988). This threshold may be modified for different types of vegetation, rain intensity and land attributes. Plant cover for the various types of vegetation is classified into three classes (Tab. 3). The vegetation quality index (VQI) is assessed as the product of the above vegeta- tion characteristics indices related to sensitivity to desertification as follows:

$\mathrm{VQI}=($ fire risk $*$ erosion protection $*$

drought resistance $*$ vegetation cover $)^{1 / 4}$

Then the vegetation quality index is classified in three levels with respect to desertification risk (Tab. 3).

In order to facilitate reading and understanding of map and to show something about the risk patterns not self-evident to the eye, ES 


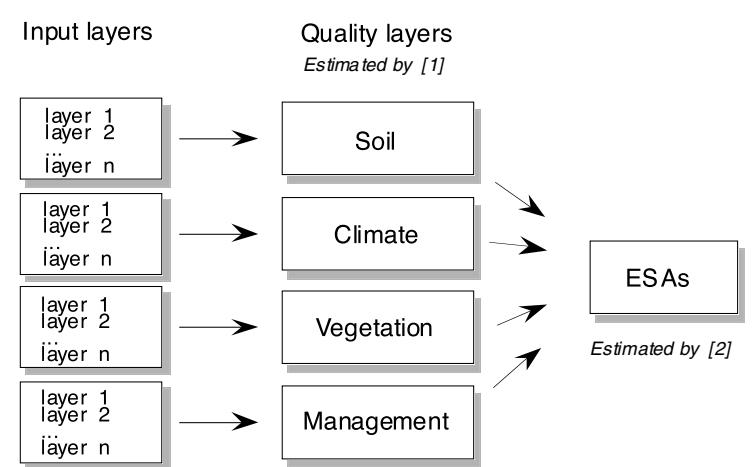

Figure 1. Scheme of the ESAs estimate (from Basso et al., 2000).

map was reclassified into a environmental degradation risk map depicting three categories of environmental degradation risk: low, high and severe risk (Fig. 3). Such classification was achieved grouping the ES values into classes discriminated by natural breaks using Jenk's optimization formula that identified within the population of ES values three break thus identifying the three aforementioned risk classes. Jenk's formula minimized the sum of the variance within each of such classes, while maximizing the difference of values between classes.

As a result of such risk classification it emerged that $19 \%$ of Basilicata landscape is exposed to high risk of environmental degradation, with major clusters of such areas located in the north of the region; medium risk is found over $41 \%$ of the total area and is mainly distributed among the eastern-central-southern Basilicata. The remaining $40 \%$ of Basilicata land is at low risk and is distributed in the western Basilicata with small clusters in the northern, central and southern areas.

\section{Analysis of main contributing factor}

Maps can be produced for each of the quality layer components. The Environmental Sensitivity of the Basilicata Region, using the method as outlined, is shown in Figure 2. The model, as implemented, is very simplified and a more complex framework, with non-linear computing and variable weighting factors, could be developed.

Once areas subjected to different risk levels (low, medium and high) were identified, we proceeded with an analytical process to identify the main contributing factor (MCF) to the environmental sensitivity in space among Basilicata's landscape (Fig. 3). The discrimination of the effect that each contributing factor may have on environmental rsik is an important aspect to consider for the decision making process in order to strategically address specific mitigation meaures towards specific factors.

Using well known raster analysis techniques, MCFs were identified at each location within Basilicata's landscape among the four quality layers (soil, vegetation, climate, management). Using the map calculator function featured in ArcGis, the enviroonmetal quality layers were processed applying a maximizing algorithm such as:

$$
\begin{gathered}
\text { OUTPUT = MAX(GRID1, GRID2, } \\
\text { GRID3, GRID4) }
\end{gathered}
$$

As a result an output grid was obtained having the same cell size and extent of the input rasters, and having for at cell the maximum value selected from the values of the correspondent cells contained in each of the four quality layers, at that same location. Such a grid was presented as a map depicting the dominance in

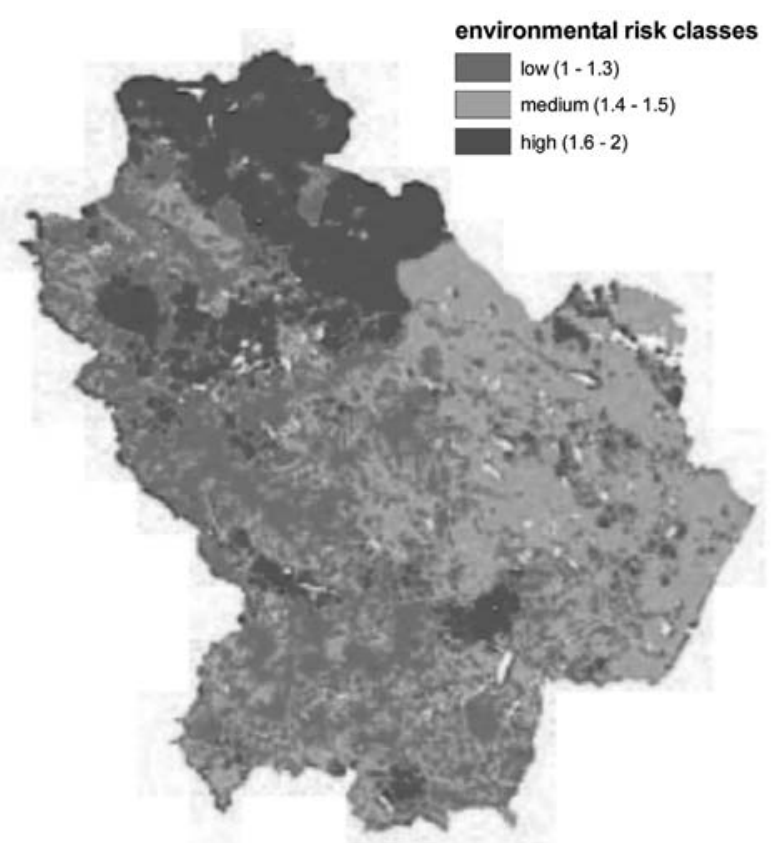

Figure 2. Basilicata environmental risk map produced using the ESA scheme represented in Figure 1. The Environmental risk map is divided in 3 classes: low, medium and high. 
space of one factor with respect to the other three.

The spatial distribution of the main contributing factors is depicted in the MCF map as shown in Figure 3. The map displays the 4 categorical classes, one for each predominat quality layer, and an extra class for those areas of Basilicata where two or more quality layers have the same impact to the final environmental risk, thus it is not possible to identy a predominant factor. After a first visual explorative analysis, the distribution of main factors exhibited some degree of similarity with that of environmental risk classes.

Cutting Basilicata's landscape from east to west in three imaginary areas, north to south oriented, we can see that management is the main contributing factor in the eastern area, vegetation is the main contributing factor in central area, while soil dominates the scenario in the western part.

A global quantitative analysis of distribution of MCF among Basilicata's landscape was carried out. It emerged that vegetation is the most responsible factor to ES over more than $50 \%$ of Basilicata's surface, soil is accounting for $31 \%$, while climate and management account respectively for almost 9 and $10 \%$. In those areas at low environmental risk, soil dominated the scenario occupying over $50 \%$ of the total surface, while vegetation and climate dominated respectively $24 \%$ and $21 \%$; management played almost no role.

Among those areas at medium risk instead, vegetation resulted to be the dominant factor over $60 \%$ of total suirface, followed by climate at $25 \%$. Soil and management played a very minor role with dominance for $10 \%$ and $5 \%$ of total area. Finally in the high risk areas, vegetation cleary dominated the scenario as dominating facctor for over $70 \%$ of total surface leaving the other factors to minor areas. Management, although dominating a minor share of $12 \%$, showed to play a more important role with respect to climate and soil, while it was almost negligible in the low and medium risk zones.

\section{Simulation of mitigation measure}

The simulation was carried out using the SALUS model (Basso et al., 2005; Basso and

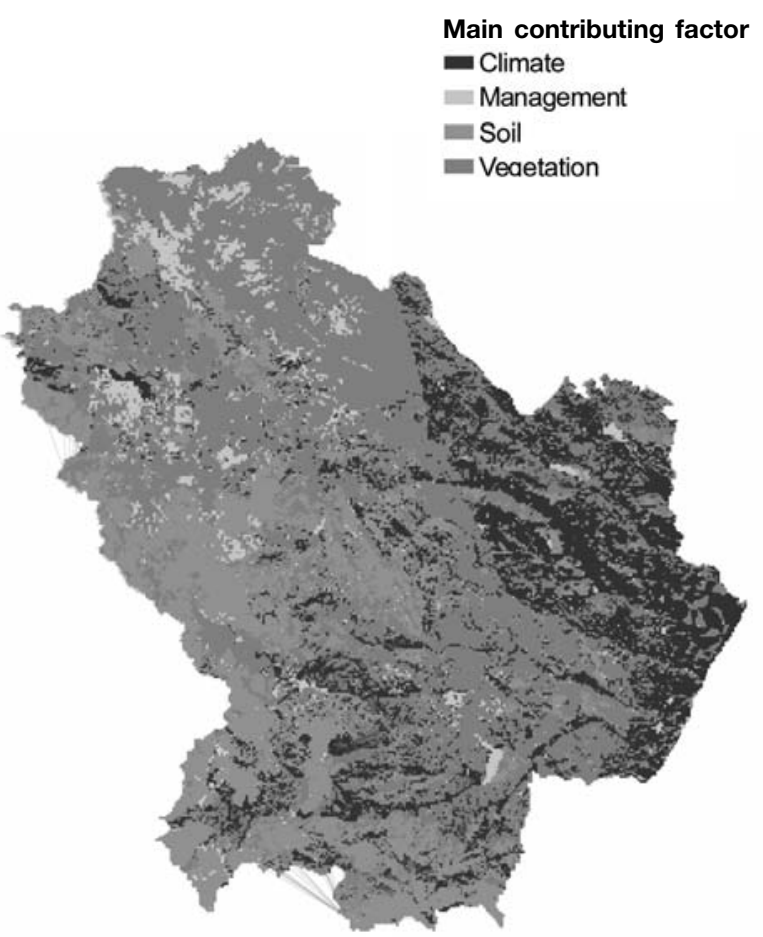

Figure 3. Basilicata map of Main Contributing Factor (MCF) to desertification processes.

Ritchie, 2005; Senthilkumar et al., 2009) with the objective of identifying the best management practice that would improve soil quality, and consequently had an effect on improved soil water infiltration, thus reducing runoff and soil evaporation. These improvements of soil characteristics where assumed to be the properties of a better climate quality layer.

From the SALUS simulated results, due to the versatile nature of the model and the setup information system, it is possible to hypothesize alternative scenarios of environmental sensitivity to degradation. An improved quality of the soil layer has been considered and a simulation has been carried out in order to quantify the resulting ES after such modification. The simulation has involved a parallel work flow of two different approaches: 1) simple increase of soil quality with non assumption on climate, 2) increase of soil quality with assumption of consequent climate quality improvement.

Basically in the former approach cell values of the soil quality layer only have been decreased to a level of low environmental sensitivity risk (and thus increased in terms of quality), while in the latter approach cell values of 


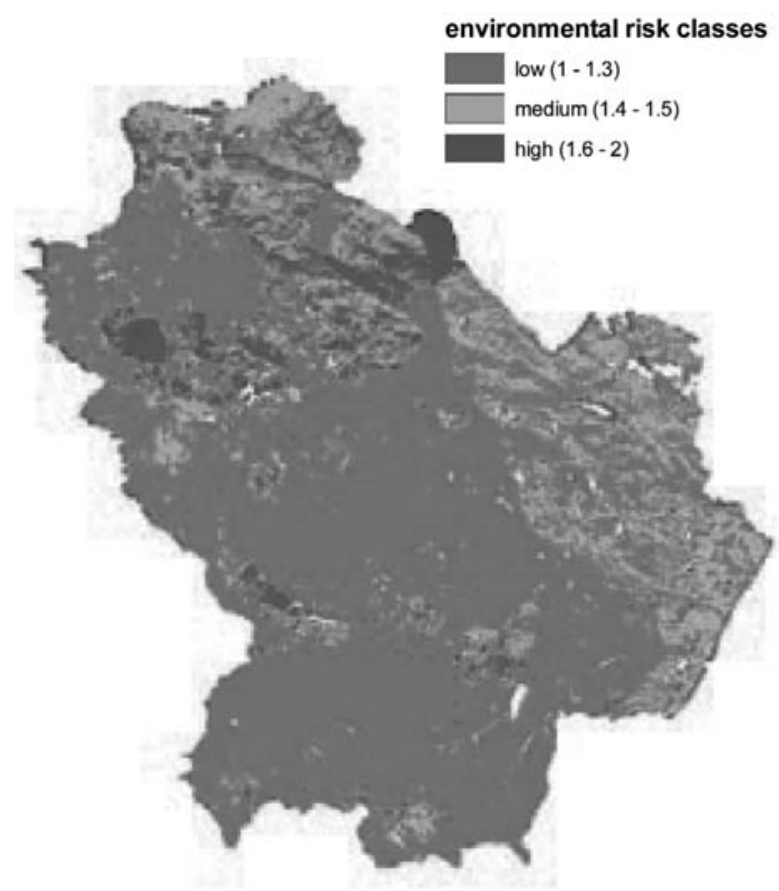

Figure 4. Basilicata ESAs map after the adoption of SALUS model (scenario 1 - improved soil quality).

the climate quality layer too have been decreased, in this case by a $25 \%$, assuming that intervention on soil will improve evapotranspiration and drainage positively influencing climate. Figure 2 shows a display of the simulation of the ES with no intervention, with intervention on soil only (Fig. 3) and with intervention on soil and climate (Fig. 4).

Once total surfaces exposed at different risk levels were assessed, and once the spatial distribution of dominating factors among such zones was quantified, a simulation was performed in order to evaluate how ameliorating one or more quality factors together would impact the extent and severity of the final environmental sensitivity of Basilicata. Such a simulation can result useful in the evaluation of effectiveness of mitigation measures.

Two scenarios were simulated hypothesizing in turn the improvement of soil quality, of soil and climate quality, and finally soil, climate and vegetation. For each scenario, the original ES model was re-run after that the specific quality layer/s was/were manipulated. Simulated results were compared with the environmental sensitivity originally calculated.

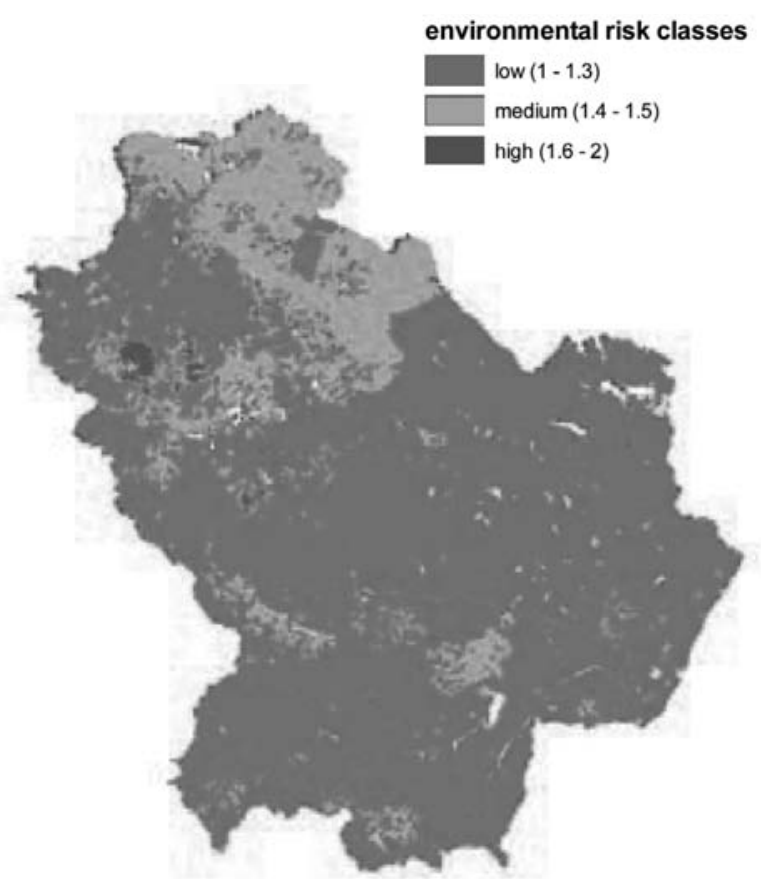

Figure 5. Basilicata ESAs map after the adoption of SALUS model (scenario 2 - improved soil and climate quality).

In the first scenario, the improvement of soil quality triggered the reduction of $63 \%$ of surfaces at high risk and reduction of $50 \%$ of surfaces at medium risk: as a result over $74 \%$ of Basilicata's landscape exhibited low risk.

In the second scenario, the enhancement of soil and climate was hypothesized. Improvement of soil through better agronomic practices can affect evapotranspiration and drainage positively. SALUS model results showed that the best management practices was found to be the one that minimizes soil disturbance and increased soil organic carbon. Figures 4 and 5 show the results of the two scenarios. As a result of the simulation, environmental risk drastically decreased: with $83 \%$ of total area exposed at low risk, $16 \%$ at medium risk, while only a negligible $1 \%$ resulted to be exposed at high risk. In turn each quality layer was first artificiously "improved" by processing the quality raster in the map calculator: each pixel (cell) value was decreased so that pixels of high risk classes would change to medium risk status, and pixels at medium risk would switch to low risk and cumulate to those pixels originally classified in such a risk class. Once the quality layers were "improved", the original ES model was re-run 
four times, each time adding an improved layer and discarding the correspondent original one.

The emphasis of this paper has been on a static system, however, degradation, sensitivity, and management are all dynamic entities. Considerable attention is currently being paid to developing the system as a continuous monitoring system in which data can be updated and compared over a range of time scales. To this extent, some layers can be considered static, whose environmental parameters change slowly, or rarely, if at all, and by their nature are infrequently measured or mapped (e.g., soil type) whilst others are more dynamic (e.g., vegetation biomass). Some data are essentially cost free and their use depends on their utility and availability (e.g., gauge station data), whilst others might be highly desirable but their cost precludes frequent updating. In any event, the aim of a such monitoring system is to define and predict trends and changes in the Environmental Sensitivity of a defined environment so as to promote efficient and optimal management.

\section{Conclusions}

The results of this study showed that through the integration of GIS and soil-plant-atmosphere system model like SALUS it is possible to identify strategies that could potentially mitigate degradation processes. The factors responsible for land degradation processes in Basilicata were identified using a GIS algorithm that allowed to further assess the weight of each factors within the environmental risk classes that were identified. The SALUS model was executed to identify the practices and the areas where the soil could have been improved. The best management practice was found to be the one that minimized soil disturbance and increased soil organic carbon. Two alternative scenarios with improved soil quality and subsequently improving soil water holding capacity were used as mitigation measures. The new ESA's map showed a significant reduction in the ES, with shifts from high to medium and low level risk classes.

\section{Acknowledgment}

This work was financed by the European Interreg Project "Moonrises: Monitoring Desertification". The authors wish to thank the reviewers for their valuable comments.

\section{References}

Basso B., Ritchie J.T., Grace P.R., Sartori L. 2006. Simulation of Tillage Impact on Soil Biophysical properties using the SALUS model. Ital. J. Agron., 4:677688.

Basso B., Ritchie J.T. 2005. Impact of animal manure, compost and inorganic fertilizer on nitrate leaching and yield in a six-year maize-alfalfa rotation. Agric. Ecosys.and Environ., 108 (329-241).

Basso F., Bellotti A., De Natale F., Ferrara A., Pisante M. 1997. Analisi del rischio di degradazione del suolo in aree agricole della Basilicata: una proposta metodologica. Rivista di Agronomia XXXI (3) Supplemento: 864-9871.

Basso F., Bove E., Dumontet S., Ferrara A., Pisante M., Quaranta G., Taberner M. 2000b. Evaluating Environmental Sensitivity at the basin scale through the use of Geographic Information Systems and Remote Sensed data: an example covering the Agri basin (southern Italy). Catena 40: 19-35.

Basso F., Bellotti A., Bove E., Faretta S., Ferrara A., Mancino G., Pisante M., Quaranta G., Taberner M. 1998. Degradation processes in the Agri Basin: evaluating environmental sensitivity to desertification at basin scale. International Seminar on "Indicator for Assessing Desertification in the Mediterranean". Porto Torres, Italy, 18-20 September.

Bryan R.B., Campbell I.A. 1986. Runoff and sediment discharge in a semi-arid drainage basin. Zeit fuer Geomorph., 58:121-143.

Danalatos N.G., Kosmas C.S., Moustakas N.S., Yassoglou N. 1995. Rock fragments II. Their impact on soil physical properties and biomass production under Mediterranean conditions. Soil Use and Management, 11:125-130.

Elwell H.A., Stocking M.A. 1976. Vegetal cover to estimate soil erosion hazard in Rhodesia. Geoderma, 15:61-70.

Faulkner H. 1990. Vegetation cover density variations and infiltration patterns on piped alkali sodic soils: Implications for the modelling of overland flow in semi-arid areas. In: Thornes J.B. (ed.): Vegetation and Erosion, Processes and Environments. J. Wiley \& Sons, Chichester, 317-346.

Ferrara A., Bellotti A., Faretta S., Mancino G., Baffari P., D'Ottavio A., Trivigno V. 2005. Carta delle aree sensibili alla desertificazione della Regione Basilicata. Forest@ 2 (1): 66-73.

Francis C.F., Thornes J.B. 1990. Runoff hydrographs from three Mediterranean vegetation cover types. In: Thornes J.B. (ed.): Vegetation and Erosion, Processes and Environments. J. Wiley \& Sons, Chichester, 363-384.

Grove A.T. 1996. Physical, biological and human aspects of environmental change. In: MEDALUS II Project 3, Managing desertification. EV5V-CT92-0165, 39-64.

Kosmas C., Danalatos N., Moustakas N., Tsatiris B., 
Kallianou Ch., Yassoglou N. 1993. The impacts of parent material and landscape position on drought and biomass production of wheat under semi-arid conditions. Soil Technology, 6:337-349.

Kosmas C.S., Moustakas N., Danalatos N.G., Yassoglou N. 1995. The effect of land land use change on soil properties and erosion along a catena. In: Thornes J.B., Brandt J. (eds.): Mediterranean Desertification and Land Use. J. Wiley \& Sons, Chichester, 207-227.

Kosmas C., Danalatos N., Cammeraat L.H., Chabart M., Diamantopoulos J., Farand R., Gutierrez L., Jacob A., Marques H., Martinez-Fernandez J., Mizara A., Moustakas N., Nicolau J.M. Oliveros C., Pinna G., Puddu R., Puigdefabregas J., Roxo M., Simao A., Stamou G., Tomasi N., Usai D., Vacca A. 1997. The effect of land use on runoff and soil erosion rates under Mediterranean conditions. Catena, 29:45-59.

Lee C.R., Skogerboe J.G., 1985. Quantification of erosion control by vegetation on problem soils. In: $\mathrm{Al}$ Swaify, Moldenhauer W.C., Lo A. (eds.): Soil Erosion and Conservation. Soil Conservation Soc. of America, 437-444.

Mitchell D.J. 1990. The use of vegetation and land use parameters in modelling catchment sediment yields. In: Thornes J.B. (ed.), Vegetation and Erosion, Processes and Environments. J. Wiley \& Sons, Chichester, 289-314.

Moustakas N.C., Kosmas C.S., Danalatos N.G., Yassoglou N. 1995. Rock fragments I. Thei effect on runoff, erosion and soil properties under field conditions. Soil Use and Management, 11:115-120.

Thornes J.B. 1988. Erosional equilibria under grazing. In: Bintliff J., Davidson D., Grant E. (eds.): Conceptual Issues in Environmental Archaeology, Edinburgh University Press, 193-210.

Senthilkumar S., Basso B., Kravchenko A.N., Robertson G.P. 2009. Contemporary Evidence of Soil Carbon Loss in the U.S. Corn Belt. Soil Sci. Soc. Amer. Jour. 73: 6- 2078-2086. 